\title{
Erratum to: Ginkgo biloba in Alzheimer's disease: a systematic review
}

Inger M. Janßen, Sibylle Sturtz, Guido Skipka, Annette Zentner, Marcial V. Garrido and Reinhard Busse

Received July 13, 2010, accepted October 11, 2010

Erratum to: Wien Med Wochenschr (2010) 160/21-22: 539-546

DOI 10.1007/s10354-010-0844-8

The surname of the author Marcial V. Garrido has been represented erroneously in a false spelling.

The paper is corrected to "Ginkgo biloba in Alzheimer's disease: a systematic review", Inger M. Janßen, Sibylle Sturtz, Guido Skipka, Annette Zentner, Marcial Velasco Garrido and Reinhard Busse.

The original version of the main topic can be found under DOI: 10.1007/s10354-010-0844-8; Wien Med Wochenschr (2010) 160/ 21-22: 539-546

Correspondence: Inger M. Janßen, MSc (Biomedical Sciences), Institute for Quality and Efficiency in Health Care (IQWiG), Dillenburger Straße 27, 51105 Cologne, Germany.

E-mail: inger.janssen@iqwig.de 